\author{
Simone Brardi ${ }^{1 *}$, Tiziano Verdacchi², \\ Giorgio Paoletti ${ }^{2}$, Vanni Giovannelli² \\ and Ennio Duranti ${ }^{1}$ \\ ${ }^{1} \mathrm{O} U$ Nephrology and Dialysis, Ospedale S. Donato, \\ Arezzo, Italy \\ ${ }^{2} \mathrm{O} U$ Urology, Ospedale S. Donato, Arezzo, Italy \\ Dates: Received: 23 September, 2016; Accepted: \\ 31 October, 2016; Published: 01 November, 2016 \\ *Corresponding author: Dr. Simone Brardi, UO. \\ Nefrologia e Dialisi - Ospedale S. Donato - Arezzo, \\ Via Fiorentina, 314, 52100 Arezzo (AR), Italy, E-mail: \\ sibrardi@gmail.com \\ www.peertechz.com \\ ISSN: 2455-5495 \\ Keywords: Diet; Kidney stones; Milk intake; Dietary \\ investigation
}

\section{Research Article \\ Does Milk Intake Play a Specific Role in the Pathogenesis of Kidney Stones?}

\section{Abstract}

Background: Diet plays a key role in the pathogenesis of kidney stones. In particular, recent findings have advanced knowledge on the protective role of a high calcium diet. However, not much is known about the specific role played by milk intake in the pathogenesis of kidney stones compared with other dairy products, especially cheese.

Methods: We conducted a retroactive case-controlled study on the eating pattern of 42 patients (29 males and 13 females) with kidney stones and 20 healthy controls (6 males and 14 females) in order to assess whether, among the various dietary factors, milk intake was involved. The entire cohort was asked to fill in a semi-quantitative questionnaire on eating habits.

Results: Logistic regression analysis at the end of the backwards selection showed that only two variables, i.e. gender and milk intake, were significantly significant, and thus retained in the final model. Kidney stones were 8.6 fold more likely to develop in subjects who drank less than one cup of milk a day compared with those who consumed more. However, milk intake was not associated with gender and age.

Conclusions: As milk has one of the lowest contents of calcium of all the dairy products, it hardly seems likely that this result can be explained solely by the higher daily calcium intake provided by increased milk intake. Further prospective studies are required on the specific relationship between milk intake and kidney stones.
\end{abstract}

\section{Introduction}

Diet plays a key role in the pathogenesis of kidney stones [1]. In particular, recent findings have advanced knowledge on the protective role of a high calcium diet in the pathophysiology of the formation of calcium oxalate stones (the most common variety). Nonetheless, not much is known about the specific action of different foods supplying calcium, in particular the specific role played by milk intake, compared with other dairy products (mainly cheese) in kidney stone formation. We performed a retroactive case-controlled study using a questionnaire to investigate the eating pattern of patients presenting kidney stones in our territory, and also to assess the role of milk intake and various dietary alimentary factors.

\section{Subjects and Methods}

\section{Study population}

Our study cohort was made up of 42 patients (21 males and 13 females) attending our lithotripsy centre and 20 healthy controls (6 males and 14 females) with no history of kidney stones. Neither taking vitamin $\mathrm{D}$ or calcium from non-dairy sources.

\section{Assessment of dietary and non dietary variables}

The entire study cohort was given a semi-quantitative questionnaire (using standard household units of weight to make the form userfriendly) to reveal the frequency and customary mean daily intake of meat (without specifying the type), salt, cheese (without specifying the type), milk (without specifying the type), pasta (without specifying the type), sugar (without specifying the type), vegetable (without specifying the type), fruit (without specifying the type) and water (without specifying the type). In addition, the variables collected for each patient and control provide demographic data (gender, age, height and weight) and information on the type of stones and the number of episodes of colic up to completion of the questionnaire (patients only) (Tables 1,2). Although the type of the kidney stones was not known in all the patients, most of the calculi analysed were calcium oxalate kidney stones, like observed in the general population (Table 1).

\section{Statistical analysis}

Descriptive analysis was performed for each variable, including frequency distribution of the variables and calculation of the elementary statistics (mean, standard deviation, minimum and maximum) for the quantitative variables in patients and controls. Distribution was determined using Chi-square tests. Student's t-test was used to assess quantitative variables. Thereafter, logistic regression analysis was performed to assess the importance of each factor on the probability of being patients or controls. In addition to food intake, BMI (calculated on weight and height and split into $\leq 25$ or $>25 \mathrm{~kg} / \mathrm{m}^{2}$ ), age ( $\leq 50$ years or $>50$ years) and gender were taken into consideration. A backwards variable selection method was adopted where $\mathrm{p}<0.05$ (Wald's test) was minimum threshold. The odds ratio and $95 \%$ confidence limits were calculated for the other variables present in the final model. All the analysis was performed using SAS V8.2 software for Windows.

\section{Results}

Frequency distributions and elementary statistics carried out to better assess the extent of the differences observed revealed that 
Table 1: Elementary statistics of patients with kidney stones and control group and frequency of episodes of colics and kidney stones.

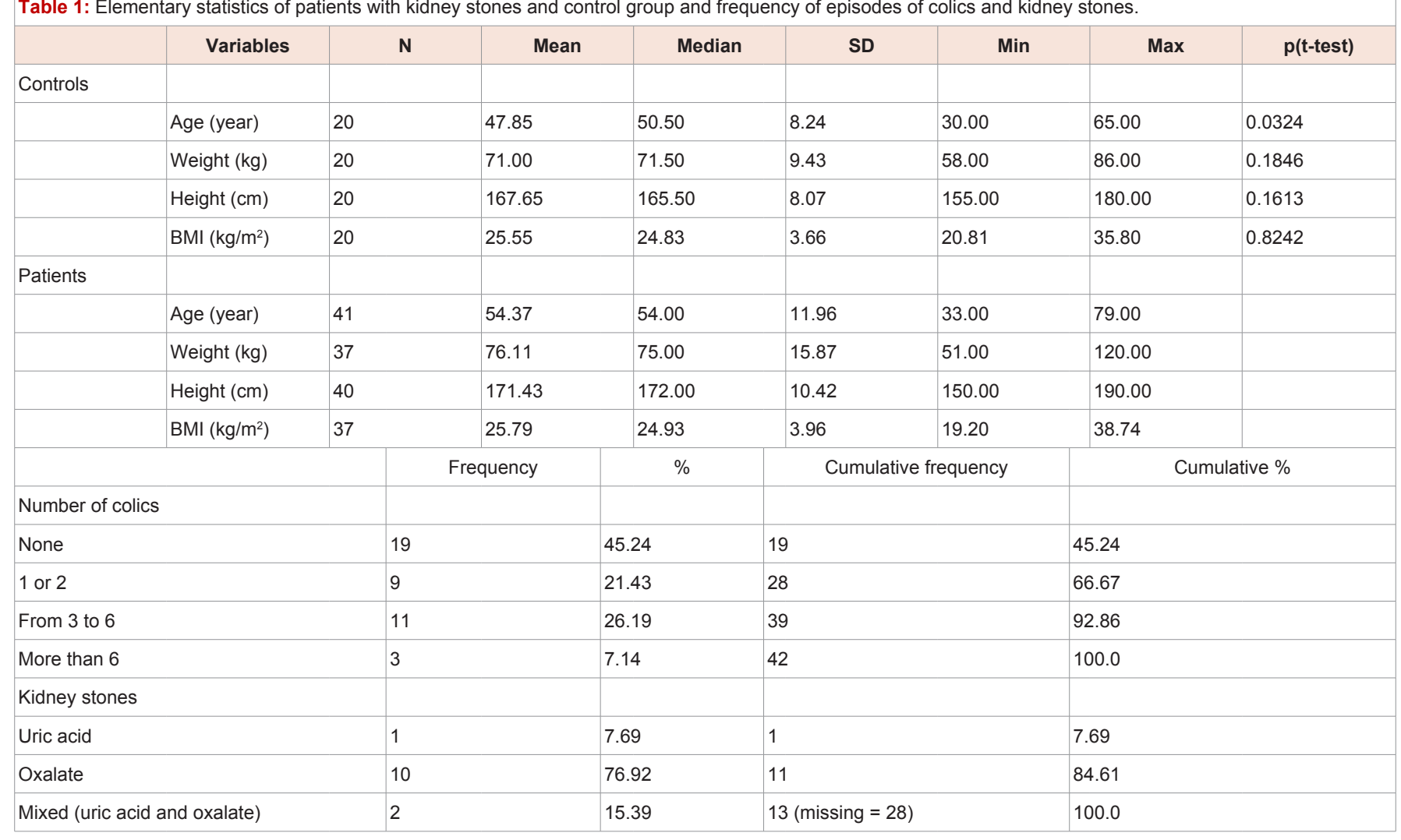

there were statistical differences in gender $(69 \%$ in male patients compared with $30 \%$ in controls), cheese intake (intake $>100 \mathrm{~g} /$ day in $7 \%$ of patients and in $25 \%$ of controls), milk intake (intake less than $1 \mathrm{cup} /$ day in patients and in $35 \%$ of controls), vegetables (more than once a day in $37 \%$ of patients and in $70 \%$ of controls) and mean age (patients $=54$ years; controls $=48$ years) $($ Tables 1,2$)$. Some of these differences may also be ascribable to sample selection, in particular demographics (age and gender). Logistic regression analysis was performed at the end of backwards selection and revealed only two significant results that were retained in the final model, i.e. gender and milk intake, and confirmed that the latter is involved in the formation of kidney stones (Table 3). Nonetheless, in view of the previously mentioned selection bias, the study did not show that also male gender was a significant risk factor: hence, this variable was retained in the model mainly to correct such bias. Formation of kidney stones was 8.6 fold more probable in subjects drinking less than one cup of milk per day compared with those who drank more: uncertainty at $95 \%$ confidence limit ranged from a minimum of 2.3 fold to a maximum of 32.6 fold (Table 3). Milk intake was not related to gender and age (Table 3). Correlation between milk intake and other food items showed significant correlations between the former and cheese and vegetables (Table 3 ). Hence, cheese and vegetable intake was not included in the logistic regression model even if, when taken individually, these are significantly correlated with the formation of kidney stones. Besides, these correlations showed a direct association for both: $72 \%$ of the entire study cohort who eats little cheese drinks less than one cup of milk per day, and $75 \%$ of the study group that eats a lot of cheese drinks at least one cup of milk per day. Analogously, yet less evidently, $78 \%$ of the study population that does not eat many vegetables drinks less than one cup of milk per day compared with $52 \%$ of those who eat a lot of vegetables (Table 3).

\section{Discussion}

Logistic regression analysis performed after the backwards selection only revealed two significant variables that were both retained in the final model, i.e. gender and milk intake (Table 3). The differences between patients and controls in age, and above all gender, may reveal a selection bias and did not show whether also male gender represents a significant risk factor, even if the literature reports that male gender is generally considered a real risk factor of renal stones [2]. Reports in the literature show that the frequency of kidney stones declines markedly after the age of 60 years and there is no longer the known inverse relationship between calcium intake and formation of calculi in subjects over 60 [3]. Therefore, we attempted to reassess the data using the criterion $\leq 60$ years or $>60$ years, but the age factor was still not significant.

Milk intake was the only dietary factor associated with the formation of kidney stones, yet due to the differences between patients and controls, this factor was not associated with gender or age (Table 3). Our study results agreed with other authors [4,5] and revealed a significant difference between cheese intake in patients and controls that seems to indicate that cheese intake negatively affects kidney stone formation. As milk has one of the lowest calcium content per one hundred grams compared with other dairy products, it is unlikely that this can be explained by a higher daily intake of milk. Diversely, the association between increased urinary uric acid 
Table 2: Distribution of single variables in patients and controls.

\begin{tabular}{|c|c|c|c|}
\hline & \multicolumn{2}{|c|}{ Frequency (\%) } & \multirow{2}{*}{ Total } \\
\hline & Control & Patient & \\
\hline \multicolumn{4}{|c|}{ GENDER $\left(x^{2}: p=0.0037\right)$} \\
\hline Female & $14(70.00 \%)$ & $13(30.95 \%)$ & 27 \\
\hline Male & $6(30.00 \%)$ & $29(69.05 \%)$ & 35 \\
\hline Total & 20 & 42 & 62 \\
\hline Less than $200 \mathrm{~g} /$ day & $18(90.00 \%)$ & $35(83.33 \%)$ & 53 \\
\hline 200 g/day or more & $2(10.00 \%)$ & $7(16.67 \%)$ & 9 \\
\hline Total & 20 & 42 & 62 \\
\hline \multicolumn{4}{|c|}{ SALT INTAKE $\left(x^{2}: p=0.8138\right)$} \\
\hline 1 teaspoonful/day & $12(60.00 \%)$ & $24(57.14 \%)$ & 36 \\
\hline 2 teaspoonful/day & $7(35.00 \%)$ & $17(40.48 \%)$ & 24 \\
\hline Total & 20 & 42 & 62 \\
\hline \multicolumn{4}{|c|}{ CHEESE INTAKE $\left(x^{2}: p=0.0499\right)$} \\
\hline$<100$ g/day & $15(75.00 \%)$ & $39(92.86 \%)$ & 54 \\
\hline$\geq 100 \mathrm{~g} /$ day & $5(25.00 \%)$ & $3(7.14 \%)$ & 8 \\
\hline Total & 20 & 42 & 62 \\
\hline \multicolumn{4}{|c|}{ MILK INTAKE $\left(X^{2}: p=0.0021\right)$} \\
\hline$<1$ cup/day & $7(35.00 \%)$ & $33(80.49 \%)$ & 40 \\
\hline 1 cup/day & $8(40.00 \%)$ & $5(12.20 \%)$ & 13 \\
\hline$>1$ cup/day & $5(25.00 \%)$ & $3(7.31 \%)$ & 8 \\
\hline Total & 20 & 41 (missing = 1) & $61($ missing = 1) \\
\hline \multicolumn{4}{|c|}{ PASTA INTAKE $\left(x^{2}: p=0.3440\right)$} \\
\hline$>100 \mathrm{~g} /$ day & $3(15.00 \%)$ & $3(7.14 \%)$ & 6 \\
\hline Total & 20 & 42 & 62 \\
\hline \multicolumn{4}{|c|}{ SUGAR INTAKE $\left(X^{2}: p=0.2810\right)$} \\
\hline$\leq 1$ teaspoonful/day & $10(50.00 \%)$ & $12(30.77 \%)$ & 22 \\
\hline 2 teaspoonful/day & $5(25.00 \%)$ & $17(43.59 \%)$ & 22 \\
\hline$>2$ teaspoonful/day & $5(25.00 \%)$ & $10(25.64 \%)$ & 15 \\
\hline Total & 20 & 39 (missing = 3) & 59 (missing = 3) \\
\hline \multicolumn{4}{|c|}{ VEGETABLE INTAKE $\left(x^{2}: p=0.0142\right)$} \\
\hline$\leq 1$ time/day & $6(30.00 \%)$ & $26(63.41 \%)$ & 32 \\
\hline$>1$ time/day & $14(70.00 \%)$ & $15(36.59 \%)$ & 29 \\
\hline Total & 20 & $41($ missing $=1)$ & $61($ missing = 1) \\
\hline \multicolumn{4}{|c|}{ FRUIT INTAKE $\left(x^{2}: p=0.4416\right)$} \\
\hline$\leq 1$ teaspoonful/day & $2(10.00 \%)$ & $9(21.43 \%)$ & 11 \\
\hline 2 teaspoonful/day & $6(30.00 \%)$ & $14(33.33 \%)$ & 20 \\
\hline$>2$ teaspoonful/day & $12(60.00 \%)$ & $19(45.24 \%)$ & 31 \\
\hline Total & 20 & 42 & 62 \\
\hline \multicolumn{4}{|c|}{ WATER INTAKE $\left(x^{2}: p=0.4653\right)$} \\
\hline$\leq 1$ teaspoonful/day & $4(20.00 \%)$ & $7(17.07 \%)$ & 11 \\
\hline 2 teaspoonful/day & $10(50.00 \%)$ & $15(36.59 \%)$ & 25 \\
\hline$>2$ teaspoonful/day & $6(30.00 \%)$ & $19(46.34 \%)$ & 25 \\
\hline Total & 20 & $41($ missing $=1)$ & $61($ missing $=1)$ \\
\hline
\end{tabular}


Table 3: Correlations between milk intake and other dietary items ${ }^{a}$ and logistic regression analysis results ${ }^{b}$.

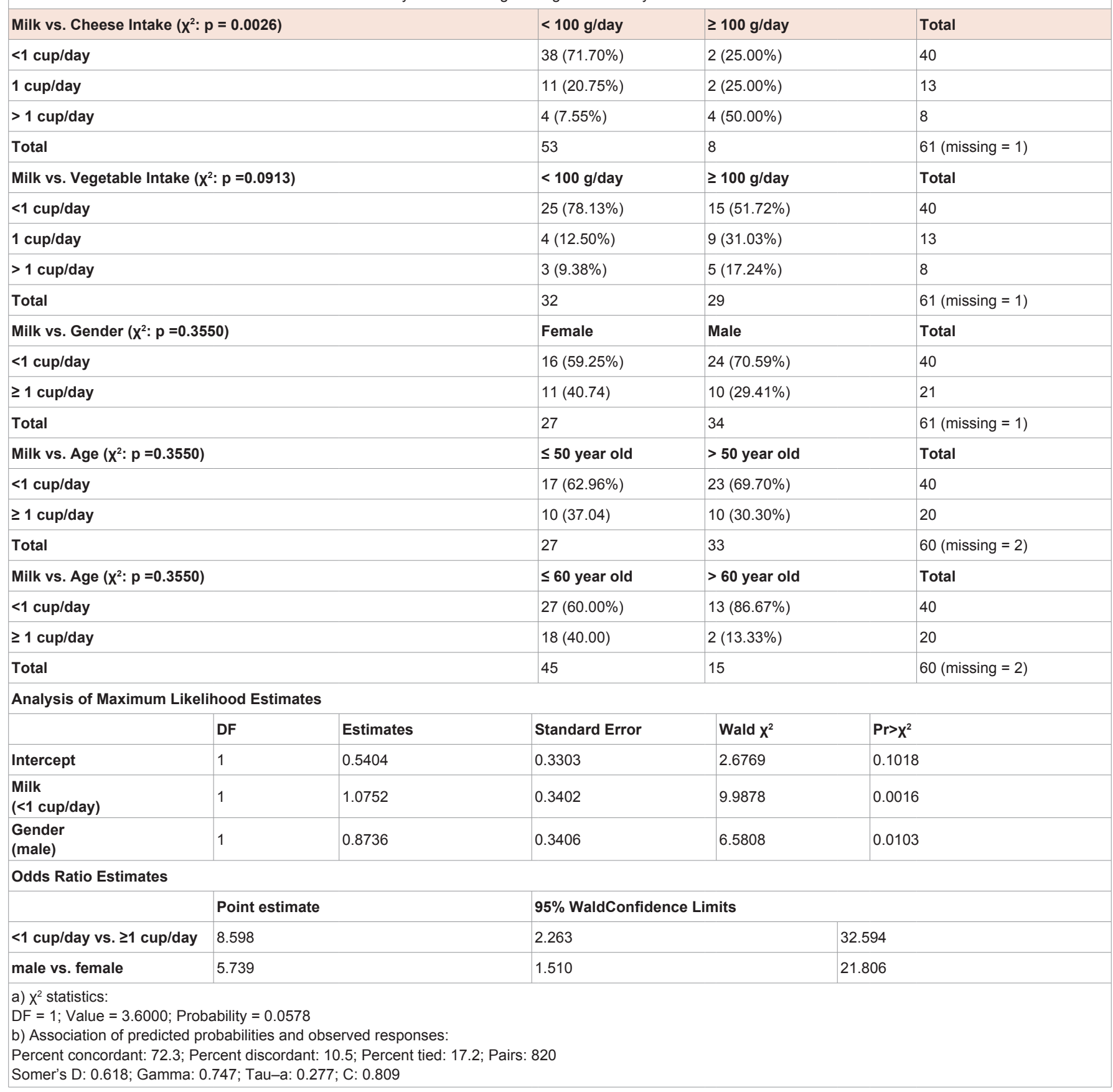

excretion and the formation of kidney stones (uric acid, or uric acid and oxalate calcium stones) is well-known [6,7]. Experimental data available are limited. A study conducted on Australian Aborigine children implies that lactose intolerance is linked with kidney stone formation (mainly urate calculi) in determining chronic metabolic acidosis that, in turn, leads to protein catabolism, increased urate excretion and thus formation of calculi [8]. A noteworthy 12-year study by Choi and coworkers on the relationship between dietary risk factors and new cases of gout [9], investigated the above-mentioned relationship in a population of 47,150 men who did not present gout when recruited in the study. Multivariate analysis revealed major inverse correlation only between skimmed milk intake (low fat yoghurt and not other dairy products) and the frequency of gout. It has been observed that milk protein intake, such as casein and lactalbumin that have uricosuric properties, reduce uricaemia levels in healthy subjects [10], whereas a four-week randomised trial of subjects on a dairy product-free diet significantly increased uricaemia levels [11]. According to Choi and coworkers [9], dairy products have a low purine content, thus milk proteins could reduce uricaemic without supplying the purine load contained in other proteins, such 
as meat and fish, even if the negative risk of elevated protein intake in kidney stone formation is common knowledge [12]. Nevertheless, the additional nutritional characteristics of milk may produce inverse associations between milk intake and kidney stones. Acids generated by food are excreted in the urine; meat and fish have a high potential renal acid load, as well as many cereals and cheese derivates. Milk and yoghurt, on the contrary, have a negative potential renal acid load. This fact means they supply alkaline ash [13]. It is common knowledge that citraturia is regulated by the acid-base balance, so intake of substances able to generate acids or alkali can influence such balance $[14,15]$. Absorption of acid or alkaline foods can therefore represent a critical factor in the regulation and elimination of citrates, and hypocitraturia, that is crucial in the pathogenesis of kidney stones $[14,15]$, can be caused by reduced intestinal total alkali absorption [14]. It is evident that the potential renal acid load of food influences urine acidity, i.e. its $\mathrm{pH}$ [16]. This is very important in the formation of urate kidney stones caused by reduced urine $\mathrm{pH}$ values that can increase indissociated uric acid concentrations and lead to the formation of uric acid calculi as well as mixed uric acid and oxalate calcium stones [6]. In our study significant differences were observed between cheese intake of patients and controls and vegetables intake (Table 2). As regards cheese, the previously mentioned protective role of the normally recommended amount of calcium in the diet must be underlined, even if our study does not fully support it. We believe that the higher vegetable intake observed in controls can be explained with the findings by Meschi and coworkers [17]. Surprisingly, we did not find significant differences between patients and controls for some dietary elements that are more closely connected with kidney stone formation, such as daily water intake and meat intake [18] (Table 2). Neither did we observe significant differences when we specifically attempted to see if meat intake was correlated with increased probability of kidney stone formation in all the entire study cohort with $\mathrm{MBI}<25 \mathrm{~kg} / \mathrm{m}^{2}$ as described in the literature [3], but this may have been due to our limited study series. We believe that water intake data are a result of the growing awareness that drinking a lot of water helps prevent kidney stones (Table 2). The non-detection of significant differences in salt and meat, as well as pasta and sugar (Table 2), are linked to cultural factors and the typical Mediterranean diet of our territory. Finally, there were no significant differences in body mass index between patients and controls, and on average the BMI was within normal limits (Table 1).

\section{Conclusions}

Further prospective studies are required on the specific relationship between milk intake and kidney stones. Besides, unlike Taylor et al. [19], we didn't allow non-dairy calcium sources such as calcium supplements or vitamin D neither we took into account the specific type of fruit or vegetables consumed [20]. Nevertheless, we believe that increased milk intake can be recommended in patients where kidney stones are directly or indirectly linked to oversaturation of urine with uric acid, as it not only supplies a higher amount of dietary calcium, but also possesses a peculiar uricosuric action as well as reduced potential renal acid load.

\section{Acknowledgements}

The authors express their appreciation to Dr. Roberto Ferrara (Statistical Service, Novartis SpA) for his helpful contribution in the statistical analysis and to Dr. Stefano Bruni and Dr. Lodovica Loschi (Medical Department, Genzyme Srl) for review of the manuscript.

\section{References}

1. Pak CY (1998) Kidney stones. Lancet 351: 1797-1801.

2. Westbury EJ (1974) Some observations on the quantitative analysis of over 1000 urinary calculi. Br J Urol 46: 215-227.

3. Taylor EN, Stampfer MJ, Curhan GC (2004) Dietary factors and the risk of incident kidney stones in men: new insights after 14 years of follow-up. J Am Soc Nephrol 15: 3225-3232.

4. Curhan GC, Willett WC, Knight EL, Stampfer MJ (2004) Dietary factors and the risk of incident kidney stones in younger women: Nurses' Health Study II. Arch Intern Med 164: 885-891.

5. Meschi T, Schianchi T, Ridolo E, Adorni G, Allegri F, et al. (2004) Body weight, diet and water intake in preventing stone disease. Urol Int 72: 29-33.

6. Abate N, Chandalia M, Cabo-Chan AV, Jr, Moe OW, Sakhaee K (2004) The metabolic syndrome and uric acid nephrolithiasis: novel features of renal manifestation of insulin resistance. Kidney Int 65: 386-392.

7. Hesse A, Tiselius H-G, Janen A (2002) Calcium oxalate stones. In: Hesse A, Tiselius HG, Janen A, editors. Urinary stones: Karger 44-71.

8. Baldwin DN, Spencer JL, Jeffries-Stokes CA (2003) Carbohydrate intolerance and kidney stones in children in the Goldfields. J Paediatr Child Health 39: 381-385.

9. Choi HK, Atkinson K, Karlson EW, Willett W, Curhan G (2004) Purine-rich foods, dairy and protein intake, and the risk of gout in men. N Engl J Med 350 1093-1103.

10. Garrel DR, Verdy M, PetitClerc C, Martin C, Brule D, (1991) Milk- and soyprotein ingestion: acute effect on serum uric acid concentration. Am J Clin Nutr 53: 665-669.

11. Ghadirian $P$, Shatenstein $B$, Verdy $M$, Hamet $P$ (1995) The influence of dairy products on plasma uric acid in women. Eur J Epidemiol 11: 275-281.

12. Borghi L, Schianchi T, Meschi T, Guerra A, Allegri F, et al. (2002) Comparison of two diets for the prevention of recurrent stones in idiopathic hypercalciuria. N Engl J Med 346: 77-84

13. Barzel US, Massey LK (1998) Excess dietary protein can adversely affect bone. J Nutr 128: 1051-1053.

14. Caudarella R, Vescini F, Buffa A, Stefoni S (2003) Citrate and mineral metabolism: kidney stones and bone disease. Front Biosci 8: s1084-1106.

15. Pak CY (1991) Citrate and renal calculi: new insights and future directions. Am J Kidney Dis 17: 420-425.

16. Remer T, Manz F (1995) Potential renal acid load of foods and its influence on urine pH. J Am Diet Assoc 95: 791-797.

17. Meschi T, Maggiore U, Fiaccadori E, Schianchi T, Bosi S, et al. (2004) The effect of fruits and vegetables on urinary stone risk factors. Kidney Int 66 : 2402-2410.

18. Curhan GC, Willett WC, Rimm EB, Stampfer MJ (1993) A prospective study of dietary calcium and other nutrients and the risk of symptomatic kidney stones. N Engl J Med 328: 833-838.

19. Taylor EN, Curhan GC (2013) Dietary calcium from dairy and nondairy sources and risk of symptomatic kidney stones. J Urol 190: 1255-1259.

20. Manfredini R, De Giorgi A, Storari A, Fabbian F (xxxx) Pears and renal stones: possibile weapon for prevention? A comprehensive narrative review. Eur Rev Med Pharmacol Sci 20: 414-425. 